\title{
Study of the Influence of Curing Processes on Mechanical Resistance Properties of Concretes
}

\author{
RHF Grillo $^{1 *}$, SC Maestrelli ${ }^{2}$ KVF Grillo ${ }^{1}$, AP Rodrigues ${ }^{1}$, MCA Pereira ${ }^{1}$ and C Oliveira ${ }^{1}$ \\ ${ }^{1}$ Federal Institute of Education, Science and Technology of the South of Minas Av Maria da Conceição Santos, Brazil \\ ${ }^{2}$ Federal University of Alfenas (UNIFAL/MG) - Rodovia José Aurélio Vilela, Cidade Universitária, Brazil
}

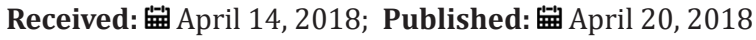

*Corresponding author: RHF Grillo, Federal Institute of Education, Science and Technology of the South of Minas Av.Maria da Conceição Santos, 900 - Parque Real, ZIPE Code - 37550-000, Pouso Alegre/MG, Brazil, Tel: 35 3427-6600; Email: rodolfo.grillo@ifsuldeminas.edu.br

\begin{abstract}
The curing process is one of the main steps after concrete molding, playing a direct role in maintenance of ideal conditions related to temperature decrease of exothermal reactions and severe environmental conditions, thus avoiding possible losses of water mass from the material to the environment. Overall the curing process must act from the initial period of microstructure formation and development, a period in which the material has low resistance properties towards tensions created from high rates of water loss leading to retraction, and micro fissures formation and development. In this work we investigated the influence of different curing processes in mechanical resistance properties of concretes aged 7, 14, 28, and 56 days. It was observed experimentally that the curing process by immersion was more efficient compared to humid and chemical curing processes, with mechanical resistance to compression values of $39.56 \mathrm{MPa}( \pm 2,23)$, that is, $24 \%$ greater. For samples not subjected to the curing process, we observed losses of $29.27 \%$ in mechanical resistance to compression. These results highlight the importance of appropriate curing processes in cement-based materials.
\end{abstract}

Keywords: Concrete; Curing processes; Resistance to compression

\section{Introduction}

Concrete in its fresh state and immediately after its packing goes through a process known as "curing"; of fundamental importance for cement-based materials to develop excellent properties in its hardened state [1]. The curing process aims to avoid loss of water mass initially added during mixing of recently cast concrete [2]. These losses are mainly due to factors such as: temperature increase, local air speed flow, direct solar incidence, and also by inadequate construction techniques frequently occurring in small scale construction sites, as premature removal of concrete mold clamps leading to deformation of structural elements. These expose new, premature concrete, to adverse environmental conditions [1]. All these factors when not minimized cause large water losses leading to materials properties loss.

\section{Water in Hydrated Cement Base}

Water classification in hydrated cement paste initially takes into account two distinct situations; the physical space it occupies and the degree of freedom it is in [1]. There are two significant ranges of the physical space; capillaries with dimensions below
$50 \mathrm{~nm}$ and regions with capillaries above $50 \mathrm{~nm}$. Regarding the degree of freedom in which water is in, there is free water and in some regions water under the influence of attraction forces on the surfaces of solid phases [2]. Taking into account the initial classification (capillary size and water degree of freedom), they are reclassified based on the degree of difficulty or easiness in which this water can be removed from the system, which are: capillary water, adsorbed water, and interlamellar water [1].

\section{Free Capillary Water}

Is the water present in empty spaces above $5 \mathrm{~nm}$, and can be described as the volume of water free from influences of forces from solid phases. In capillaries with dimension above $50 \mathrm{~nm}$ there is a water volume termed "free water", characterized by not being under the action of attraction forces from solid surfaces [3]. Taking into account these two characteristics; capillary dimensions and water degree of freedom, this region is of utmost importance considering the cementitious materials' microstructure, in which supposedly, the curing process acts with a greater importance. By avoiding 
significant water loss during the desired concrete properties can thus be guaranteed by the end of the hydration process [4].

Removal of water within this region does not alter the volume even for concrete dosed with high rate of $w / c$, in which under these conditions the volume of excess water will probably not be consumed by the hydration process, leading to the material developing porosity throughout the whole microstructure as a consequence of evaporation of this water [1]. Inadequate water loss within this region impairs the whole hydration process of the cement particle. Water shortage in the material still in its fresh state interrupts hydration, and as a consequence there is formation of a microstructure with low properties related to an incomplete process in the formation of solid phases, preventing the material from reaching the mechanical resistance pre-established in the dosing process [2].

\section{Capillary Water Under Strong Influence of Attraction Forces}

Within capillaries below $50 \mathrm{~nm}$, water can be under the action of attraction forces exerted by surfaces of solid phases in formation, and are usually hard to remove, such as

Adsorbed water: Water found near the surface of solids under the influence of attraction forces;

Interlamellar water: water associated to specific structures within the $\mathrm{CSH}$ gel, suggested as a monomolecular water layer between the layers of the CSH gel, strongly retained by hydrogen bonds. Interlamellar water is lost only under conditions of low humidity and as a consequence the structure retracts considerably [3].

Water removal in these two conditions is linked to the application of a greater force in which the water is subjected to by the solid phases or by hydrogen bonds in the CSH structure. Application of this force on the material in the initial period, that is, during the microstructure formation process, leads to development of microfissures in the cement matrix [3]. Fissures related to retraction of the material develop as a function of tension relief as the material with little curing time does not have sufficient resistance to support high tensions originated as a consequence of removal of this water by external agents. This fissures cause great losses on concrete properties causing permeability, loss of durability, and when located within the transition zone potentiate reduction of mechanical resistance properties characteristic of this region $[3,5]$.

\section{Plastic Retraction, Retraction of Thermal Origin and Autogenous}

The study of the phenomenon of retraction in cement-based materials can be described as the plastic deformation that occurs throughout a period of time in recently molded material, without loading influences. It is associated with water movement as loss of water mass or when working with concrete dosages of very low w/c ratio, in which a supposed "water loss" occurs by hydration of the cement particle. Concrete retraction is termed as plastic, of thermal origin, and as of autogenous origin [1].

Plastic retraction occurs within the initial instants of concrete application, before the formation of solid phases and is characterized by high rates of water loss in fresh material; great loss of water volume within a short period of time in concrete with low resistance. Environmental conditions and the degree of freedom in which water is in (free of influences from external forces) are the major factors responsible for the removal of this water and as a consequence in the development of the plastic retraction process. This type of retraction is intrinsic to concrete dosed with high water/cement ratios and in mixing processes in which water reduction additives are not used, allowing part of the water used in mixing to be retained among the cement flakes [1].

Retraction of thermal origin is associated with water loss from the system as a function of temperature increase within the concrete; local temperature during concrete pouring added to exothermic reactions from the hydration process of the cement particles. Temperature elevation due to exothermic reactions during the hydration of cement is conditioned to the amount of clinker in the cement composition and particle size distribution; higher clinker ratios and finer particles will always develop high temperatures [5]. This problem is associated to conformation of structures that demand large volumes of concrete such as dams, and foundation blocks, among others. Soon following conformation there is the formation of a temperature gradient between the structural element's interior and its surface. Concrete temperature in the interior of the structural element will always be higher when compared to its surface where heat exchange with the external environment occurs more efficiently, thus lowering the temperature in this external region [6]. Another factor that acts in parallel to this problem is the variation in local external temperature, a situation that calls for more caution.

Large external temperature variations within short time frames act directly in the temperature gradient of the recent conformed element $[2,4]$. Regions with elevated temperatures interact with the concrete resulting low heat exchange with the environment; a more favorable situation on the other hand is seen in regions of high environmental temperature variations in which heat exchange occurs intensively leading to the formation of tensions known as tensions of thermal origin causing great property losses specially related to the durability of the concrete [4].

Retraction of autogenous origin is characterized by the loss of humidity (water) that is subjected to action of attraction forces on the surfaces of solids within the micropores, as lamellas of $\mathrm{CSH}$ gel and capillaries with dimensions below $5 \mathrm{~nm}$. This water is not evaporated from the system except in special conditions of 
humidity, but consumed by the hydration process of the cement particles. Therefore, retraction of autogenous origin occurs at a much higher frequency specially in concretes with low water/ cement ratio with a few specific characteristics when compared to retraction of thermal origin; autogenous retraction develops in a isotropic way from within the concrete while retraction of thermal origin occurs from the surface to the element's nucleus. Also, there is no humidity gradient in the autogenous retraction while in the thermal retraction in which the temperature gradient is characteristic there is also the formation of a humidity gradient given water is removed from the exterior towards the interior parts of the element [3].

\section{Curing Processes In Concrete}

Norm ABNT NBR 5738, establishes criteria of curing for the determination of the mechanical resistance properties in concrete samples prepared in the laboratory. Curing processes can be carried out by two methods: by immersion in which the test cylinder is immersed in a saturated solution of calcium hydroxide (water + calcium hydroxide) with temperature of $23+/-2{ }^{\circ} \mathrm{C}$, or in a humid chamber with temperature of $23+/-2 \stackrel{\circ}{\circ} \mathrm{C}$ and relative humidity superior to $95 \%$ [7]. This curing processes are unfeasible for application in armed concrete structures, and thus non-normalized materials and application techniques are adopted with the specific aim of maintaining the initial dose of water content used in concrete fabrication, protecting it from conditions of low humidity, high temperatures and wind action $[7,8]$. These techniques encompass four curing processes: curing under normal temperature conditions; favorable environmental conditions avoids water removal from the system, usually used in colder regions and with high local humidity. Thermal curing; this method usually employs a chamber that creates favorable high humidity and temperature conditions. Humid curing; the most feasible technique for application in structures of armed concrete, the most efficient process in harsh environmental conditions, this most popular process consists in saturating with water the whole concrete structure's surface neutralizing the effects of elevated temperatures, wind, among others. Its efficacy is directly related to the time span of application. Chemical curing; this process relies on application of a material on the surface of the structural elements closing the surface pores and thus avoiding water loss to the environment $[1,7,8]$.

\section{Materials and Methods}

The experimental methods involved the characterization of the materials and fabrication of concrete in which different curing processes were analyzed in terms of mechanical resistance to compression in four curing periods. For preparation of concrete it was used cement Type CP II E 32 superplasticizer additive of polycarboxylate base and as aggregate stone dust and gravel number one both from Pouso Alegre, MG, Brazil. For the chemical curing process it was used the MasterKure curing agent from Basf S/A. The characterization of the cement involved qualitative chemical analysis and its major physical and mechanical properties, for the aggregates determination of water absorption, and for concretes it was determined the mechanical resistance to compression after periods of 7, 14, 28 and 56 days with four bodies of proof per curing period.

Following 24 hours of test cylinder molding, part of the samples was exposed to environmental conditions without the application of a curing process while the remaining of the samples was subjected to three distinct curing processes: curing by immersion conforming to Norm ABNT NBR 5738, humid curing; the process with greater technical feasibility for application in armed concrete structures. For these essays the concrete samples remained exposed to environmental conditions and were wetted twice a day by morning and by afternoon for a period of 7 days, and chemical curing during which the concrete bodies of proof also stayed exposed to environmental conditions, were not wetted and the process to avoid water loss involved the application of the curing agent MasterKure on the external area of the test cylinder closing its porosity on the sample's surface region thus avoiding water loss to the environment.

\section{Results and Discussion}

Results on the physical characterization of the cement are listed in Tables 1 \& 2, and reveal interesting results regarding the hydration process. The cement particle hydration kinetics, the development of mechanical resistance with little curing time and high rates of heat exchange are related to the granulometry of the cement, in which smaller particles hydrate faster.

Table 1: Physical characterization of the cement.

\begin{tabular}{|c|c|c|c|}
\hline & Norm & Holcim & $\begin{array}{c}\text { Limits of } \\
\text { NBR } \\
\text { 11578/91 }\end{array}$ \\
\hline Strainer mesh of $75 \mu(\%)$ & NBR 11579/91 & 4.4 & $\leq 10$ \\
\hline $\begin{array}{c}\text { Water in paste of Standard } \\
\text { consistency }(\%)\end{array}$ & NBR NM 43/03 & 25.0 & -- \\
\hline Initial catch time (h:min.) & NBR NM 65/03 & $03: 45$ & $\geq 1 \mathrm{~h}$ \\
\hline End of catch time (h:min.) & NBR NM 65/03 & 05:00 & $\leq 10 \mathrm{~h}$ \\
\hline Elapsed time (h:min) & -- & 01:15 & -- \\
\hline $\begin{array}{l}\text { Permeability to air ( Blaine } \\
\left.\qquad \mathrm{m}^{2} / \mathrm{kg}\right)\end{array}$ & NBR NM 76/98 & 385 & $\geq 380$ \\
\hline Specific mass $\left(\mathrm{g} / \mathrm{cm}^{3}\right)$ & NBR NM 23/01 & 3 & -- \\
\hline Expansability (mm) & $\begin{array}{l}\text { NBR NM } \\
11582 / 91\end{array}$ & 0.5 & $\leq 5$ \\
\hline
\end{tabular}


Table 2: Results of cement mechanical resistance to compression.

\begin{tabular}{|c|c|c|c|c|c|c|c|}
\hline \multicolumn{8}{|c|}{ CEMENT CPII E 32 - Resistance to Compression (MPa) - (NBR 7215/96) } \\
\hline \multirow{2}{*}{$\begin{array}{l}\text { Period } \\
\text { (days) }\end{array}$} & \multicolumn{4}{|c|}{ Test Cylinder Number } & \multirow{2}{*}{ Mean Mpa } & \multirow{2}{*}{$\begin{array}{l}\text { Maximum } \\
\text { error (\%) }\end{array}$} & \multirow{2}{*}{$\begin{array}{c}\text { NBR11578/9 } \\
\text { Limits }\end{array}$} \\
\hline & 1 & 2 & 3 & 4 & & & \\
\hline 3 & 21.1 & 21.2 & 21.3 & 21.9 & 21.4 & 2.3 & $\geq 10$ \\
\hline 7 & 29.3 & 29.9 & 28.5 & 27.9 & 29.9 & 3.5 & $\geq 20$ \\
\hline 28 & 38.6 & 39.8 & 38.5 & 37.7 & 38.7 & 2.8 & $\geq 32$ \\
\hline
\end{tabular}

We verified in the results of the cement physical characterization shown in Tables $1 \& 2$ very few particles with dimensions above 75 $\mu \mathrm{m}$, with results of initial time span for curing of $3 \mathrm{~h} 45 \mathrm{~min}$ reaching normal consistency established by the norm for this assay, with only $25 \%$ of water content. These results point out that cement with good hydration kinetics gain mechanical resistance quicker and display interesting heat exchange rates as a consequence of exothermal reactions. Water absorption by the aggregates in the

From the results it was verified that the amount of water retained in terms of percentage was greater for finer aggregates indicating a greater quantity of permeable capillary pores when compared to larger aggregates. Elevated capillary porosity on the aggregate demands addition of water during concrete fabrication. However it cannot be ascertained whether the water retained in the interior of the aggregate capillaries can generate porosity on the Table 4: Composition of concretes. saturated condition on the dry surface is listed in Table 3 and was performed according to Norm NBR NM 53 for large aggregates, and for small aggregates following Norm NBR NN 30.

Table 3: results of aggregate water absorption.

\begin{tabular}{|c|c|}
\hline Material & Water absorption (\%) \\
\hline Finer aggregates & 4.78 \\
\hline Larger aggregates & 2.91 \\
\hline
\end{tabular}

hydrated cement paste and cause any loss on mechanical resistance properties. Not taking this into account in the aggregates water absorption assay on in relation to the cement paste leads to loss of a fraction of the calculated water during mixing, reducing the cement particle hydration. Table 4 presents the composition of the materials used in fabrication of the concretes.

\begin{tabular}{|c|c|c|c|c|c|c|c|}
\hline \multicolumn{8}{|c|}{ Dosage Per Batch - 30 Liters 16 Test Cylinders } \\
\hline Identification & $\mathbf{w} / \mathbf{c}$ & Cement (kg) & Add & & Stone Dust (kg) & Gravel (kg) & Water (L) \\
\hline $\mathrm{CH}^{*}$ & 0.347 & 13.55 & $0.4 \%$ & 54 & 30.72 & 27.61 & 4.7 \\
\hline \multicolumn{8}{|c|}{$\mathrm{CH}^{*}$ - Concrete made with cement brand HOLCIM } \\
\hline
\end{tabular}

Table 5 presents the results on mechanical resistance to compression for concretes with different curing processes. Results on mechanical resistance to compression clearly show the efficiency Table 5:Results on mechanical resistance to compression as a function of the curing process.

\begin{tabular}{|c|c|c|c|c|c|c|c|c|}
\hline \multirow{2}{*}{ Period (Days) } & \multicolumn{6}{|c|}{ Curing Process } & \multirow{2}{*}{\multicolumn{2}{|c|}{ No Curing CH-R }} \\
\hline & \multicolumn{2}{|c|}{ Immersion CH-I } & \multicolumn{2}{|c|}{ Humid CH-U } & \multicolumn{2}{|c|}{ Chemical CH- Q } & & \\
\hline \multicolumn{9}{|c|}{ Mechanical resistance to compression (MPa) } \\
\hline 7 & 31.56 & \pm 2.04 & 27.76 & \pm 3.35 & 24.78 & \pm 3.44 & 23.89 & \pm 3.44 \\
\hline 14 & 36.76 & \pm 2.92 & 30.56 & \pm 3.48 & 27.89 & \pm 4.39 & 24.89 & \pm 4.39 \\
\hline 28 & 38.88 & \pm 1.52 & 31.78 & \pm 3.48 & 28.56 & \pm 4.39 & 26.78 & \pm 4.39 \\
\hline 56 & 39.56 & \pm 2.23 & 33.67 & \pm 4.14 & 29.97 & \pm 3.92 & 27.98 & \pm 3.22 \\
\hline
\end{tabular}

The efficiency of the curing process by immersion established by Norm NBR 5738 can be attested by the superiority of the results and is related to the efficiency of avoiding water loss from the material which is expected for this process once it involves immersion of the test cylinder in water neutralizing to the maximum temperature elevation and from external environmental stressors. However despite the superior results there is a constraint on the application of this process; the technical unsuitability for application in armed concrete structures. By analyzing the other of the curing process by immersion when compared to other curing processes. two curing processes it was observed a slight superiority for the process involving humid curing, in which the mechanical resistance results were more interesting. This superiority can be associated to two main factors: during the humid curing of the test cylinders Where subjected to application of water twice, thus allowing for a reduction of concrete temperature during wetting and also with the saturation of superficial pores there is maintenance of humidity throughout the whole curing period. 
The curing process in concrete structures can present greater efficiency when there is intense wetting during application or by reducing wetting intervals when outside temperatures are higher. In chemical curing different then in humid curing the material has its temperature raised over time exposed to environmental actions such as solar incidence, high local temperature and winds. There is no wetting, making the concrete temperature reach elevated peaks in a critical initial period, during microstructure formation. This way the efficiency of the chemical curing is related to the closure of pores on the concrete surface but it does not minimize external actions, presenting greater efficiency in protected environments which normally do not occur with armed concrete structures in vertical buildings.

\section{Conclusion}

Through the assays performed it was possible to observe the importance of the curing process in the fabrication of cement-based materials, in which samples not subjected to any curing process presented great reduction in properties of mechanical resistance to compression, as revealed by intensive water loss. Taking into account the three curing techniques employed, the results of mechanical resistance to compression indicate a slight superiority of curing by immersion, established by Norm ABNT NBR 5738. This process restricts influence of external factors in which the concrete stays completely immersed, thus avoiding any loss of water from the system. Its drawback however is the difficulty in application especially in armed concrete structures such as girders and pillars.

Humid curing process presented more interesting results on mechanical resistance then those obtained with chemical curing. The efficiency of this process in avoiding water loss allowed humid curing to develop microstructures with superior properties of mechanical resistance. This way, the chemical curing process obtained the lowest performence in avoiding significant water losses in structers exposed to environmental conditions, presenting the least efficient results on mechanical resistance to compression among the different methods tested.

\section{Acknowledgement}

The authors thank CAPES and FAPEMIG for financial support of this research.

\section{References}

1. PK Mehta, PJM Monteiro (2008) Concreto: Microestrutura, Propriedades. ( $2^{\text {nd }}$ edn.); São Paulo. IBRACON, Brazil, pp. 674.

2. PC Atcin (2000) Concreto de Alto Desempenho. Pini pp. 667.

3. ANM Lopes (2011) Mitigação da retração autógena em concretos de altas resistências contendo aditivo redutor de retração e seus efeitos na macro e microestrutura. Tese Doutorado, Universidade Federal Rio Grande do Sul, Porto Alegre.

4. B Tutikian, VA Cecconello (2012) Influência das baixas temperaturas na evolução das resistências do concreto. Artigo revista IBRACON de ESTRUTURAS E MATERIAIS 5(1): 68-83.

5. GCR Garcia, EMB Santos, SPC Ribeiro (2014) Efeito do tempo de cura na rigidez de argamassas produzidas com cimento Portland. Artigo, Cerâmica 57: 94-99.

6. TC Cervo, TJ BALDO Estudo da forma de cura de concretos de Alto Desempenho em sua resistência à tração na flexão. Artigo, Escola Politécnica da Universidade de São Paulo, São Paulo, p. 1-12.

7. (2001) ABNT-NBR MN 30: Agregado miúdo - Determinação da absorção de água. Rio de janeiro.

8. (2009) ABNT-NBR NM 53: Agregado Graúdo - Determinação da massa específica, massa específica aparente e absorção de água, Rio de janeiro.

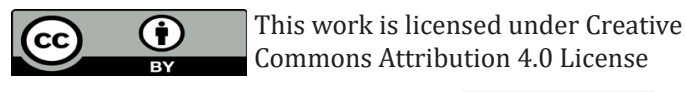

To Submit Your Article Click Here:

Submit Article
DOI: $10.32474 /$ TCEIA.2018.02.000128

Citation: RHF G, SC M, KVF G, AP R, MCA P, C 0. Study of the Influence of Curing Processes on Mechanical Resistance Properties of Concretes. 